\title{
Engaging Virtual Learning Environment System to Enhance Communication and Collaboration Skills among ASEAN Higher Education Learners
}

\author{
http://dx.doi.org/10.3991/ijet.v11i04.5503 \\ Jintavee Khlaisang ${ }^{1}$ and Kemmanat Mingsiritham ${ }^{2}$ \\ ${ }^{1}$ Chulalongkorn University, Bangkok, Thailand \\ ${ }^{2}$ Sukhothai Thammathirat Open University, Nonthaburi, Thailand
}

\begin{abstract}
The study aims to design and develop a Virtual Learning Environment (VLE) system to enhance the communication and collaboration skills of higher education learners in the ASEAN cultural community. The system was developed based on a literature review of ASEAN to identity its educational goals for 2015, as well as the subjects of open learning, VLE, active learning, activity based learning, ASEAN cultural community, and collaboration and communication skills in $21^{\text {st }}$ century. The results of the literature review were developed into a questionnaire for 400 higher education instructors. The survey results were then tabulated using $G^{*}$ Power and were analyzed using Exploratory Factor Analysis (EFA) to find the core elements to be developed to be an appropriate VLE system. The resulting system was tested using a sample group of 30 volunteer undergraduate students from 5 ASEAN member countries. Data analysis using t-test dependent indicated that there was statistical difference between pre and post self-assessment scores of the $21^{\text {st }}$ century skills in communication and collaboration at a 0.05 level of significance. The result was consistent with the results of behavior and trace observations and the quality of project assignments produced using the system. The system developed consisted of four elements was approved by experts in the education field.
\end{abstract}

Index Terms-ASEAN, Collaboration, Communication, Higher Education, Virtual Learning Environment

\section{INTRODUCTION}

Since 2003, the use of the Virtual Learning Environment (VLE) has steadily increased in higher education [1], and it has been widely promoted for a range of subjects including strategic planning and educational activities. The technology employed has been the Learning Management System (LMS), mainly in the form of proprietary software and open source or in-house software. However, research shows that VLE has thus far mostly been used as an optional learning tool for students. Also, it was found that a number of innovative technologies are widely used in VLE including wireless and mobile technologies. VLE, LMS and three-dimensional virtual world, have been largely used to promote social interaction when students actively participate in assigned tasks and activities [2]. It has also been proven that the use of VLE can enhance the cognitive skills of higher education learners as well as respond to important issues of education, including selfpaced learning and lifelong learning that are emphasized in preparing learners for technology and cognitive skills development [3].
Both educators and learners have deemed VLE more effective than traditional learning which is often lecturebased. Also, VLE has helped reduce the learning gaps of students living in remote areas. In addition, VLE can be used as a self-study method. The current research has found that students in a Virtual Learning Environment were mostly satisfied with this type of learning because they could control their learning by skipping the familiar content and focusing on the complicated material. This is a major benefit of VLE compared to traditional classrooms or lecture-based instruction [4].

There are a number of benefits of the use of VLE to strengthen communication and collaboration skills in the ASEAN environment. Since VLE can increase the value of sharing and exchanging ideas at the global level, especially among communities with different cultures, it allows for the establishment and maintenance of online communities through the use of technology without time and place constraints [5]. Multiple studies have revealed the effective uses of VLE for learning. One such study found that VLE enhances students' engagement, motivation, and learning outcomes [6]. Another found that the use of VLE can promote collaboration and communication by means of exchanging ideas, sharing thoughts, and exploring information together, as opposed to only being used to meet individual learning achievement goals [7]. This is relevant to Thai government policies which promote adaptation to the global environment. One such policy seeks to address the rapid global changes in the aspects of the advancement of information technology and societal changes. This will be important for Thailand since at the end of 2015 it became part of the ASEAN Economic Community which seeks to improve cooperation among the ASEAN countries to increase global competitiveness. To succeed in this new environment, it will be necessary for higher education learners to be able learn and cooperate with others, communicate well to produce desired outcomes, and develop themselves to their full potential [8]. Achieving this goal will require that students be part of a network of learning which can cross boundaries through the use of technology [9]. In 2013, the current study was conducted with higher education students in ASEAN and it was found that VLE helped enhance communication and collaboration skills at a .05 level of significance using self-evaluating form, collaboration observation, and rubric for innovative project. [10]. 


\section{REVIEW OF THE LITERATURE}

The use of the Virtual Learning Environment (VLE) in higher education has continually expanded as VLE has helped enhance student's capacities via attractive technology and challenging tools appropriate for the digital generation [1]. VLE covers a large area including web pages, Learning Management Systems (LMS), Learning Content Management Systems (LCMS), the three-dimensional virtual world, and Social Networking Sites [3]. In Japan, VLE has been used as a web 2.0 tool, which along with Social Networking Sites (SNS), has provided an online community for language learning and promoted learning collaboration among foreign language learners. In one study in Japan, the class consisted of master's students (2 Japanese, 2 Chinese, 1 American, and 1 Serbian). The results showed that SNS can promote language learning through community building as it allows learning to occur between members at different times. This environment led students to change their roles from passive learners to active learners. However, students required time to adapt to this use of technology. Other web-based tools that could help facilitate learning were the development of courseware and the use of VLE in the form of LMS to increase the role of students and to create knowledge via their community and which allowed content publishing and communication [11].

It is clear that VLE can be adapted to incorporate specialized content to draw its strengths and to boost the learning competencies of learners. A case study in Finland which compared traditional lecture-based instruction with VLE on the subject of occupational safety was conducted. This study used a form of VLE called Virtu, which consisted of 2 main features: an E-textbook for studying theory and doing exercises, and a "virtual enterprise" consisting of 1) visits to the enterprise and 2) description of the enterprise in simulation form. The analysis results indicated that students who learned via VLE required less study time and achieved higher scores than those using traditional learning methods. Students thought that Virtu did not provide too much information and they were able to control the speed of studying by themselves. Compared to traditional lectures, this group of students viewed the best part of the program as being the group work. They felt it brought the subject closer to real life and they were confident in the quality of the content. Although they studied in different sections, they received the same quality of teaching. As for the use of time, VLE was found to be more time-saving and provide more effective learning [4].

One of the benefits of the virtual community is that it can increase the value of sharing and exchanging ideas at both local and global levels, especially among communities with different cultures, as it allows for the establishment and maintenance of online communities through the use of technology [5]. Thailand is one of the countries that have emphasized the use of technology to enhance learning within the ASEAN community. Therefore, to enable the students to understand and recognize the societal and cultural aspects of ASEAN, challenging activities must be created using an active learning approach and activitybased learning. Students should be involved in groupwork, and collaborating through online communication that allows learners to study with learners from other countries and create their own online community. Such activities would result in the development of both com- munication and collaboration skills. To achieve this, clearly integrating technology with teaching will be critical.

The current research focuses on learning in a Virtual Learning Environment which can be accessed anywhere via any platform such as a smart phone or tablet, and thus will enable learners to access learning anywhere, anytime and receive feedback from instructors in a timely manner. The expected results of this research are not only to provide a system that enables students to learn more about the culture and society of ASEAN through VLE, but also to provide an opportunity for students to understand and be a part of a learning culture, exchange knowledge to acquire the $21^{\text {st }}$ century skills in communication and collaboration, and express readiness to be a leader within the increasingly integrated ASEAN community.

\section{Aim Of ThE STUdy}

The aim of this study is to develop a VLE system with special features applicable for the ASEAN context, as higher education based on enhancing $21^{\text {st }}$ century skills in communication and collaboration which are important skills for entering the ASEAN community in 2015. Based on the aim of the study, research questions are as follows:

1. What are input elements of the system identified from using Exploratory Factor Analysis to create a theoretical model to be developed into a VLE system?

2. What are the appropriate input processes for a system of teaching and learning management for learners in the $21^{\text {st }}$ century? These input processes are identified through a survey of users' readiness and needs assessment developed as a basis for the development of the VLE.

3. To what extent does the VLE system enhance $21^{\text {st }}$ century skills in communication and collaboration in the ASEAN community?

\section{RESEARCH METHODOLOGY}

The research design used in this study is Research and Development (R\&D) aiming to develop a VLE system to enhance the $21^{\text {st }}$ century skills in communication and collaboration of higher education learners in the ASEAN cultural community. The process was divided into 3 phases as follows:

1. Develop the theoretical Model in order to determine the appropriate input elements for a VLE system for the ASEAN Cultural Community based on the results of needs assessment obtained from the analysis of elements in communication and collaboration using Exploratory Factor Analysis.

2. Explore the input processes of the VLE in order to determine the most effective method of teaching and learning management to enhance the communication and collaboration skills of ASEAN higher education learners. The results of a survey of users' readiness and needs assessment were used in the design of the main process for the development of VLE.

3. Examine usage results, evaluate, and present the VLE system developed to enhance the communication and collaboration skills of higher education learners in ASEAN cultural community. 


\section{A. Participants}

A sample group was used to determine the appropriate inputs which were the elements obtained from Exploratory Factor Analysis of the learning and teaching process for the $21^{\text {st }}$ century learner. A needs assessment of users was conducted to create the theoretical model for developing the virtual learning environment system. The subjects included 400 higher education instructors out of a total of 153,499 under the Office of Higher Education Commission [12]. The sample size (n) was determined by using $\mathrm{G}^{*}$ Power with the confidence level at $95 \%$, error at $\pm 5 \%$, power of test at 0.95 , medium effect size $(0.25)$, with five analysis groups. There were 305 people in the sample group with 400 valid questionnaires, which was determined to be an appropriate sample size for generalized analysis.The sample group in the study to test the VLE system were 30 students from 5 countries: Myanmar, Cambodia, Philippines, Vietnam, and Thailand. The group was selected by random sampling as required by the research and comprised undergraduate students interested in ASEAN cultural exchange and had who had at least 5 years' experience in ICT.

\section{B. Measurement}

The instruments used in this study were: (1) a questionnaire with 94 questions in 2 parts. Part 1 was general information about the instructors (6 questions) and Part 2 was about knowledge of pedagogy and technology in the context of the environment of virtual learning to enhance learning and innovation skills and communication and collaboration (88 questions), (2) A Learning Management System with plug-ins to enhance skills in communication and collaboration. This utilized open source software and an online community using Open Simulator, and (3) a usage evaluation form including (3.1) a students' selfevaluation form which had 37 items that were relevant to the results of the Exploratory Factor Analysis, (3.2) a behavioral observation form for communication and collaboration (Behavioral observation form) using a 4 point scale $(0,1,2$, and 3), (3.3) an evaluation form for assignments regarding communication and collaboration and an evaluation form regarding innovation. The evaluation for assignments used rubric criteria which was divided into four levels $(0,1,2$, and 3$)$. Elements considered were (1) communication and collaboration skills, (2) the elements of the assignments considered the objectives and content, media and learning resources, activities and evaluation, and education theory, (3) the design and development of the assigned project and (4) the delivery and completion of the assignments. The evaluation of innovation had elements which included: (1) standards in the process of developing innovations in communication and collaboration, (2) the value of the assignments, and (3) the standards for innovation.

\section{Background of the Study: Demographics and Needs Assessment}

The analysis of the sample group and the analysis of communication and collaboration elements to study the needs of instructors and students in higher education for the design and development of a VLE system can be summarized as follows.

The demographics of the sample group were female (55.25 percent) and male (44.75 percent). The largest group was between $31-40$ years old (48.75 percent), fol- lowed by $41-50$ years olds (29.25 percent). The majority of respondents had the highest education as a master's degree ( 54.25 percent), followed by a doctoral degree ( 44 percent). Most were lecturers ( 70.25 percent), followed by assistant professors (24.75 percent). Most respondents worked in public or autonomous universities (51.00 percent), followed by branches of Rajabhat University (46.00 percent). The largest group had teaching experience of at least 6 years (30.25 percent), followed by $6-10$ years (28.50 percent).

Needs Assessment: Analysis of communication and collaboration elements are as follows:

1. Basic statistics of communication and collaboration show that the average scores of 88 communication and collaboration element items were between 3.558 and 4.458, and the standard deviation was between 0.710 and 1.055 .

2. The analysis of communication and collaboration elements conducted via a questionnaire using Principal Component Analysis and Orthogonal Rotation using Varimax Method show that:

2.1 The Kaiser-Meyer-Olkin and Bartlett's Test of Sphericity indicate that the data from the sample group was appropriate to be analysed for communication and collaboration elements.

2.2 Communality analysis indicates that communal value before extracting elements using Principal Component Analysis (PCA) of every question was 1.000. After extracting elements, the value was higher than 0.20 . This means that the questions were appropriate for the element analysis.

2.3 When considering the Eigen Value which is higher than 1.00, there were 9 elements. Considering 9 elements, the accumulated variance of the 9 elements were 78.970 percent of the total variance.

2.4 When considering the elements from 2.3 which had values higher than 0.50 . Each element had to have more than three variables to be considered as 1 element. Therefore, there were 4 prominent elements, including element $1,2,3$, and 4 , which accounted for 83 variables in total.

2.5 Element naming. Element 1 had 38 variables. This element was named "Teaching Techniques and Collaborative Supporting Media". Element 2 had 26 variables. This element was named "Communication Tools". Element 3 had 11 variables. This element was named "Collaborative Learning". Element 4 had 8 variables with element weight of between 0.569 to 0.841 and Eigen Values at 2.812. It consisted of 4 variables on teaching models which were $1,2,3$, and 4. There were 3 variables on teaching method. This element was named "Roles".

\section{RESEARCH FINDINGS}

Research findings were divided into 3 parts according to the research methodology. The details are as follows:

1) Develop the theoretical Model in order to determine the appropriate input elements for a VLE system for the ASEAN Cultural Community based on the results of a needs assessment from the analysis of elements in communication and collaboration using Exploratory Factor Analysis. 


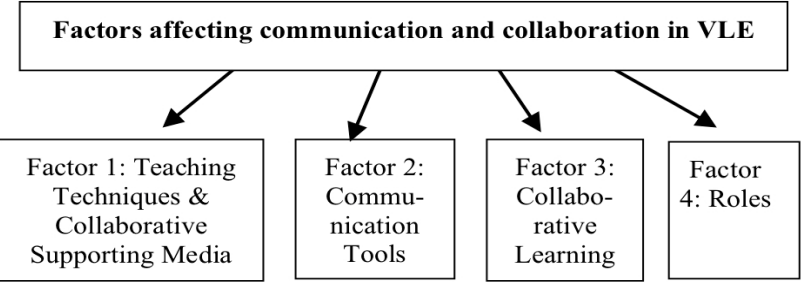

Figure 1. Factors affecting communication and collaboration in VLE from needs assessment using Exploratory Factor Analysis

The results of the needs assessment from the analysis of elements in communication and collaboration using Exploratory Factor Analysis reveal 4 core elements: (1) Teaching Techniques and Collaborative Supporting Media, (2) Communication Tools, (3) Collaborative Learning, and (4) Roles. There were 83 relating variables. Based on the analysis results, the researcher organized a focus group to screen 83 variables to develop another process as shown in Fig. 1 and Table 1.

Based on the screening results, there were 83 variables to be incorporated into the system and used in determining the workflow for the development and design in the next step. Fig. 2 shows the workflow of the relation of the system design and learning management to enhance the communication and collaboration skills for learners. Table III shows the design and development process to enhance learning of $21^{\text {st }}$ century skills in communication and collaboration, event details, and associated elements. 2) Explore the input processes of the VLE in order to determine the most effective method of teaching and learning management to enhance the communication and collaboration skills of ASEAN higher education learners.

Examination of the input processes of the VLE was done by using the results of the survey of users' readiness and needs assessment which were developed and further used for the design of the main process for the development of VLE. Then, the system design of teaching and learning management was developed as a workflow to show the relationship of factors with the processes to enhance $21^{\text {st }}$ century skills in communication and collaboration. The workflow was approved by 15 experts from the focus group. It was then used to develop a prototype of the system, site structure, activity plan, system manual, and evaluation form to examine the system in the next step. The results of input processes of the VLE consisted of 7 processes as shown in Fig. 2 and detailed in Table III. The site structure of the VLE system is shown in Fig. 3.

According to Fig. 3, the highlight of the developed VLE system is that it was designed and developed with the purpose to be offered to the public free of charge based on the need to develop VLE system in ASEAN context.

The advantage of this system is that it is an open source system which allows users to use, share, and improve upon the system according to their needs at no cost to themselves. The system consists of (1) Moodle Learning Management System (LMS), Virtual Learning Environment (VLE), Video Conference System: Red5, and Social media, and (2) learning contents for 10 ASEAN member countries, namely ASEAN Food Module in the form of video streaming, e-books, as well as Open Educational Resources (OER). The system enables students from 10 ASEAN countries to exchange knowledge through various activities. The activities focus on not only communication
TABLE I.

CORE ElEMENTS AND MEANING

\begin{tabular}{|l|l|}
\hline \multicolumn{1}{|c|}{ Elements } & \multicolumn{1}{c|}{ Meaning } \\
\hline $\begin{array}{l}\text { Factor 1: Teaching } \\
\text { Techniques and } \\
\text { Collaborative } \\
\text { Supporting Media }\end{array}$ & $\begin{array}{l}\text { Teaching techniques and collaborative supporting } \\
\text { media is the combination of various teaching } \\
\text { techniques with collaborative support media, } \\
\text { focusing on new media in a digital format that } \\
\text { encourages students to learn while working togeth- } \\
\text { er. }\end{array}$ \\
\hline $\begin{array}{l}\text { Factor 2: Commu- } \\
\text { nication Tools }\end{array}$ & $\begin{array}{l}\text { Tools to facilitate communication and collaboration } \\
\text { to be more effective. Instructors will prepare the } \\
\text { tools to facilitate students to learn and communi- } \\
\text { cate more effectively, especially in the context of } \\
\text { the ASEAN cultural community. }\end{array}$ \\
\hline $\begin{array}{l}\text { Factor 3: Collabo- } \\
\text { rative Learning }\end{array}$ & $\begin{array}{l}\text { Students can participate in the learning process } \\
\text { with others. They will define their own role and } \\
\text { respect other students' roles for effective learning. }\end{array}$ \\
\hline Factor 4: Roles & $\begin{array}{l}\text { Students can learn together in a group process } \\
\text { where they are aware of their roles. Students can } \\
\text { communicate together in a group and decide to- } \\
\text { gether under the agreement of the group effectively } \\
\text { with the advice and guidance of instructors. }\end{array}$ \\
\hline
\end{tabular}

TABLE II

CORE ELEMENTS AND RATIONALE FOR VARIABLE SCREENING

\begin{tabular}{|c|c|}
\hline Elements & Rationale for variable screening \\
\hline $\begin{array}{l}\text { Factor 1: Teaching } \\
\text { Techniques and } \\
\text { Collaborative } \\
\text { Supporting Media }\end{array}$ & $\begin{array}{l}\text { The results of variable screening which are suitable } \\
\text { for the context are experiential learning, active } \\
\text { learning, case study-based learning, simulating } \\
\text { scenario-based learning, setting questions, practice } \\
\text { in activity, self-learning, and learning and assess- } \\
\text { ment of real conditions. Media supporting collabo- } \\
\text { rative learning included Word processing and e- } \\
\text { books, which are the media that the researcher } \\
\text { prepared for students via Moodle Learning Man- } \\
\text { agement System (LMS). The system focuses on } \\
\text { mobile technology as a virtual classroom with an } \\
\text { open simulator program to collect learning media } \\
\text { and help develop a virtual environment. It also } \\
\text { helps connect students from five ASEAN countries } \\
\text { better. }\end{array}$ \\
\hline $\begin{array}{l}\text { Factor 2: Commu- } \\
\text { nication Tools }\end{array}$ & $\begin{array}{l}\text { The results of variable screening which are suitable } \\
\text { for the context are tools for supporting Moodle e- } \\
\text { learning. Multimedia emphasizes the use of open } \\
\text { education resources, videos on the Internet, mobile } \\
\text { learning, web video conference, and web applica- } \\
\text { tions. The researcher prepared communication tools } \\
\text { for students through Moodle LMS. The system } \\
\text { focuses on mobile technology as a virtual class- } \\
\text { room with open simulator program to collect } \\
\text { learning media and help develop a virtual environ- } \\
\text { ment. It also helps connect students from five } \\
\text { ASEAN countries in a learning process that sup- } \\
\text { ports communication and collaboration. }\end{array}$ \\
\hline $\begin{array}{l}\text { Factor 3: } \\
\text { Collaborative } \\
\text { Learning }\end{array}$ & $\begin{array}{l}\text { The results of variable screening which are suitable } \\
\text { for the context are brainstorming learning, activity- } \\
\text { based learning, role setting, group work, participa- } \\
\text { tion in the activity, and the exchange of experienc- } \\
\text { es through various communication tools in social } \\
\text { online community. }\end{array}$ \\
\hline $\begin{array}{l}\text { Factor 4: } \\
\text { Roles }\end{array}$ & $\begin{array}{l}\text { The results of variable screening which are suitable } \\
\text { for the context are project-based learning, collabo- } \\
\text { rative learning, cooperative learning, group process } \\
\text { learning, communicating together in the group, } \\
\text { making decisions together, analyzing data together, } \\
\text { and coming to agreements together. These elements } \\
\text { are sub-elements that will affect the roles of both } \\
\text { students and instructors. }\end{array}$ \\
\hline
\end{tabular}


ENGAGING ViRTUAL LEARNING ENVIRONMENT SYSTEM TO ENHANCE COMMUNICATION AND COLLABORATION SKILLS...

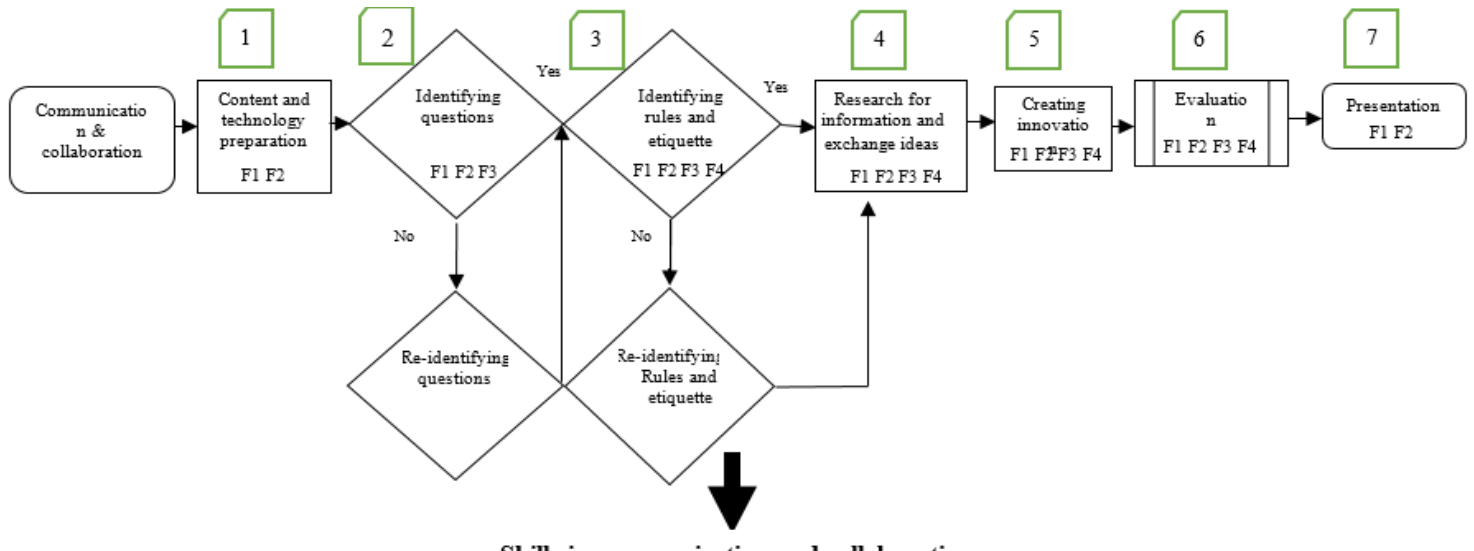

Skills in communication and collaboration

Factor 1Teaching Techniques and Collaborative Supporting Media | Factor 2Communication

Tools | Factor 3Collaborative Learning | Factor 4 Roles

$\begin{array}{llll} & =\text { Start/end } & \rightarrow & =\text { Data flow } \\ & =\text { Sub process } & \text { F1 } & =\text { Factor } 1 \\ & =\text { Decision point } & \text { F2 } & =\text { Factor } 2 \\ & =\text { Data input } & \text { F3 } & =\text { Factor } 3\end{array}$

Figure 2. Workflow of relationship of the system design of teaching and learning management to enhance $21^{\text {st }}$ century skills in communication and collaboration

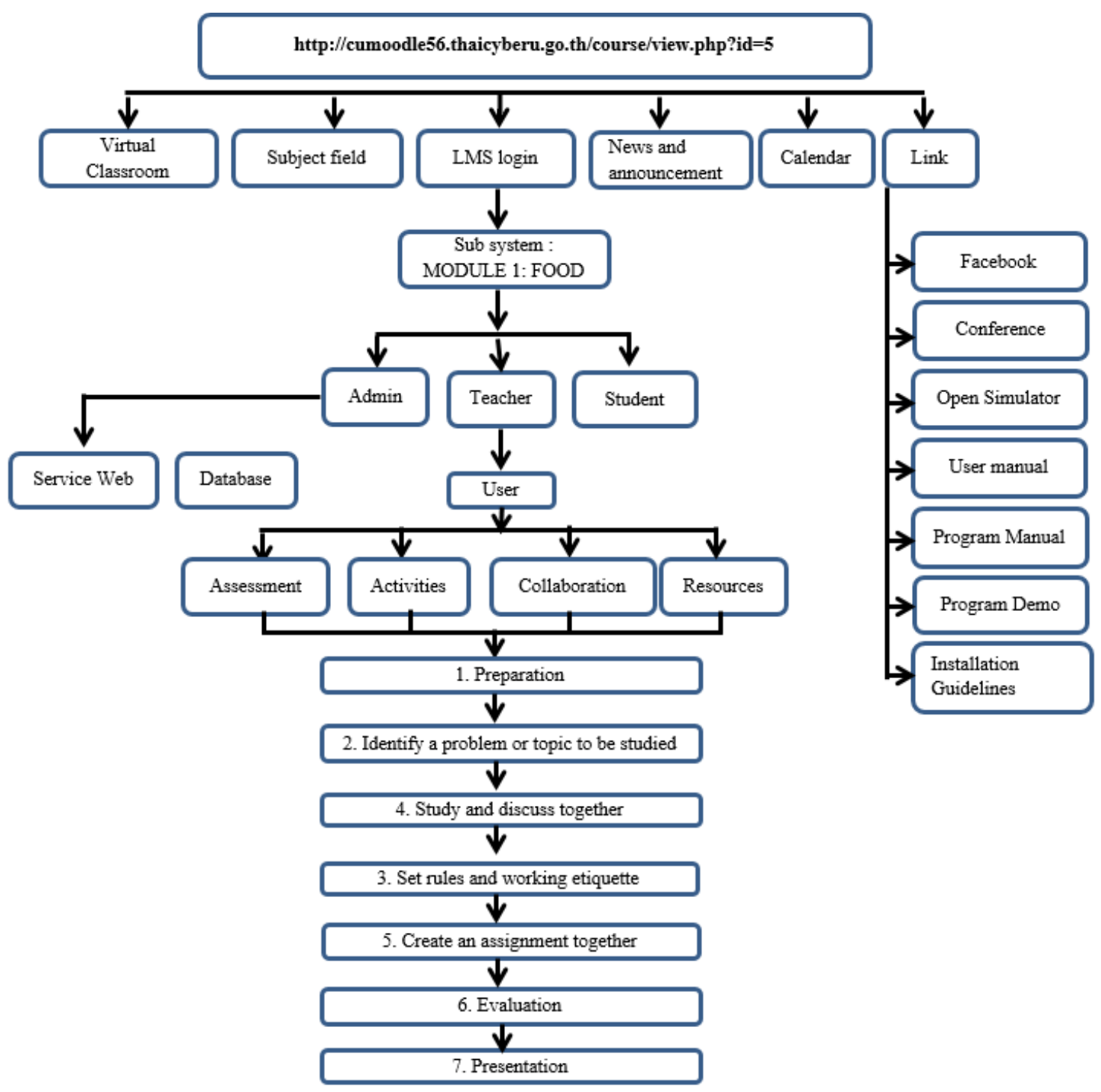

Figure 3. Site Structure of the VLE system 
TABLE III.

The Design And DeVelopment Process Of A LEARning System To ENHANCE $21^{\text {ST }}$ CEnTURy SkILLS IN COMMUNICATION AND COLLABORATION, ACTIVITIES, AND ELEMENTS

\begin{tabular}{|c|c|c|}
\hline Design \& development process of the system & $\begin{array}{c}\text { Activity-based learning and active learning in a Virtual Learning } \\
\text { Environment }\end{array}$ & $\begin{array}{c}\text { Elements to be } \\
\text { designed \& devel- } \\
\text { oped }\end{array}$ \\
\hline Step 1: Preparation (Technology \& Content) & \multirow[b]{2}{*}{$\begin{array}{l}\text { Activity 1: Nice to meet you (Technology preparation) } \\
\text { 1. Students learn how to use Moodle and do learning activities in Moodle. } \\
\text { 2. Students write an introduction of himself/herself and upload their profile } \\
\text { and picture to Moodle to introduce themselves to other students. } \\
\text { 3. After writing their introduction, students learn about other students' } \\
\text { profile and form a group of } 3-5 \text { students. There must be } 2-3 \text { Thai students } \\
\text { and 1-2 foreign students in a group. Use VLE: Open simulator for a group } \\
\text { chat. }\end{array}$} & \multirow{3}{*}{$\begin{array}{l}\text { Factor } 1 \\
\text { Factor } 2\end{array}$} \\
\hline $\begin{array}{l}\text { VLE Tools } \\
\text { (Community Tools): } \\
\text { 1. LMS : Moodle } \\
\text { 2. VLE : Open simulator }\end{array}$ & & \\
\hline $\begin{array}{l}\text { Learning Resource Tools (Self-paced): } \\
\text { 1. Streaming Video } \\
\text { 2. E-Books } \\
\text { 3. Open Content }\end{array}$ & $\begin{array}{l}\text { Activity 2: You're a chef (Content preparation) } \\
\text {.1Students learn about national dishes of ASEAN in Moodle. } \\
\text { 2. Students write down main ingredients in the national dishes of ASEAN } \\
\text { countries and find the similarities and differences of ingredients in national } \\
\text { dishes. Do the assignment in VLE: Open simulator. } \\
\text { 3. After finishing 'You're a chef' activity, students submit their answer, } \\
\text { then read every answer of other students in their group in Moodle. }\end{array}$ & \\
\hline Step 2: Choose an issue or topic to be studied & \multirow[b]{2}{*}{$\begin{array}{l}\text { Activity 3: The Best Menu } \\
\text { 1. Each student in a group presents a national dish that they are interested } \\
\text { in using information from online resources. Do the assignment in VLE: } \\
\text { Open simulator. } \\
\text { 2. After each group selecting a national dish, uploads their answer to } \\
\text { Moodle to share with other students so every group has different national } \\
\text { dishes. }\end{array}$} & \multirow{2}{*}{$\begin{array}{l}\text { Factor } 1 \\
\text { Factor } 2 \\
\text { Factor } 3\end{array}$} \\
\hline $\begin{array}{l}\text { VLE Tools } \\
\text { (Community Tools): } \\
\text { - Same as above } \\
\text { Learning Resource Tools (Self-paced): } \\
\text { - Same as above }\end{array}$ & & \\
\hline Step 3: Set working rules & \multirow[b]{2}{*}{$\begin{array}{l}\text { Activity 4: Our Menu \& Your Duty } \\
\text { 1. Students join the group to do activities set by the instructor and create } \\
\text { group working rules. } \\
\text { 2. Students describe themselves briefly explaining their personalities and } \\
\text { characteristics to find a suitable role in filming a national dish video. Do } \\
\text { the assignment in VLE: Open simulator. } \\
\text { 3. After assigning the role to each student, upload information to Moodle } \\
\text { for the instructor. }\end{array}$} & \multirow{2}{*}{$\begin{array}{l}\text { Factor } 1 \\
\text { Factor } 2 \\
\text { Factor } 3 \\
\text { Factor } 4\end{array}$} \\
\hline $\begin{array}{l}\text { VLE Tools } \\
\text { (Community Tools): } \\
\text { - Same as above } \\
\text { Learning Resource Tools (Self-paced): } \\
\text { Same as above }\end{array}$ & & \\
\hline Step 4: Study information and share ideas & \multirow[b]{2}{*}{$\begin{array}{l}\text { Activity 5: Making Storyboard } \\
\text { 1. Students in a group create a working plan and share ideas on a story- } \\
\text { board for the ASEAN national dish video (I-Streaming Video). The form } \\
\text { of the video is not limited but it has to answer the question 'What is the } \\
\text { distinct feature of your dish and how it is similar to other ASEAN national } \\
\text { dishes?' Complete the assignment in VLE: Open simulator. } \\
\text { 2. After finishing writing a storyboard, each group uploads it to Moodle for } \\
\text { the instructor. }\end{array}$} & \multirow{2}{*}{$\begin{array}{l}\text { Factor } 1 \\
\text { Factor } 2 \\
\text { Factor } 3 \\
\text { Factor } 4\end{array}$} \\
\hline $\begin{array}{l}\text { VLE Tools } \\
\text { (Community Tools): } \\
\text { - Same as above } \\
\text { Learning Resource Tools (Self-paced): } \\
\text { Same as above }\end{array}$ & & \\
\hline Step 5: Do an assignment & \multirow[b]{2}{*}{$\begin{array}{l}\text { Activity 6: Enjoy Eating } \\
\text { 1. Students film their ASEAN national dish video (I-Streaming Video) } \\
\text { following the storyboard that was submitted to the instructor. Students } \\
\text { perform the role set previously. } \\
\text { 2. After filming and editing the video, upload and share the video to Moo- } \\
\text { dle for the instructor. }\end{array}$} & \multirow{2}{*}{$\begin{array}{l}\text { Factor } 1 \\
\text { Factor } 2 \\
\text { Factor } 3 \\
\text { Factor } 4\end{array}$} \\
\hline $\begin{array}{l}\text { VLE Tools } \\
\text { (Community Tools): } \\
\text { - Same as above } \\
\text { Learning Resource Tools (Self-paced): } \\
\text { Same as above }\end{array}$ & & \\
\hline Step 6: Evaluation & \multirow{2}{*}{$\begin{array}{l}\text { Activity 7: Replay } \\
\text { 1. Students evaluate the video of their group (I-Streaming Video) to see if } \\
\text { there is anything to edit or change in VLE: Open simulator. } \\
\text { 2. Students edit the video according to the group evaluation and upload the } \\
\text { edited file to LMS: Moodle. }\end{array}$} & \multirow{2}{*}{$\begin{array}{l}\text { Factor } 1 \\
\text { Factor } 2 \\
\text { Factor } 3 \\
\text { Factor } 4\end{array}$} \\
\hline $\begin{array}{l}\text { VLE Tools } \\
\text { (Community Tools): } \\
\text { - Same as above } \\
\text { Learning Resource Tools (Self-paced): } \\
\text { Same as above }\end{array}$ & & \\
\hline Step 7: Presentation & \multirow[b]{2}{*}{$\begin{array}{l}\text { Activity 8: Learning Log } \\
\text { 1. Students study and watch the video of every group uploaded in Moodle. } \\
\text { 2. After finishing watching the video, each student does an individual } \\
\text { activity. } \\
\text { - Proactive activity: 'Learning Log'. Each student summarizes information } \\
\text { getting from the video, discussing similarities and differences of ASEAN } \\
\text { national dishes in VLE: Open simulator. } \\
\text { 3. Summit the paper to the instructor in LMS: Moodle. }\end{array}$} & \multirow{2}{*}{$\begin{array}{l}\text { Factor } 1 \\
\text { Factor } 2\end{array}$} \\
\hline $\begin{array}{l}\text { VLE Tools } \\
\text { Community Tools: } \\
\text { - Same as above } \\
\text { Learning Resource Tools (Self-paced): } \\
\text { - Same as above }\end{array}$ & & \\
\hline
\end{tabular}

Factor 1 = Teaching Techniques and Collaborative Supporting Media,

Factor $2=$ Communication Tools,

Factor 3 = Collaborative Learning, and

Factor $4=$ Roles 
and collaboration skills, but also learning skills, including critical thinking and problem solving, as well as comparing the similarities and differences of innovations, which will support the creation of innovations that will strengthen ASEAN Identity. The main screens of the system with tools are shown in Fig. 4 and Fig. 5.

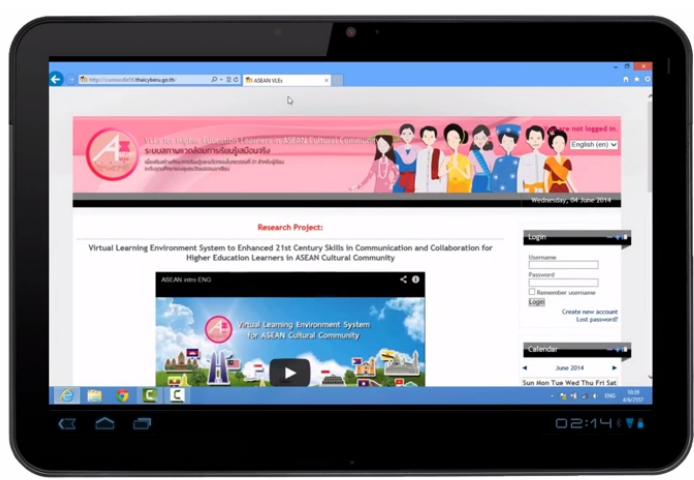

Figure 4. System displaying on the tablet

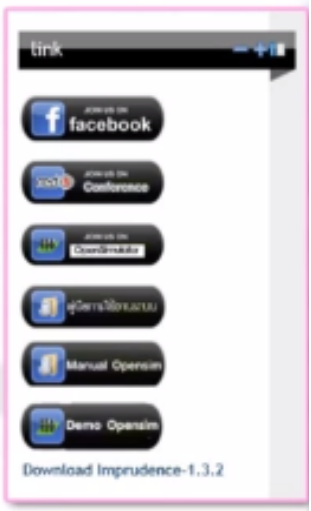

Figure 5. Tools in the system

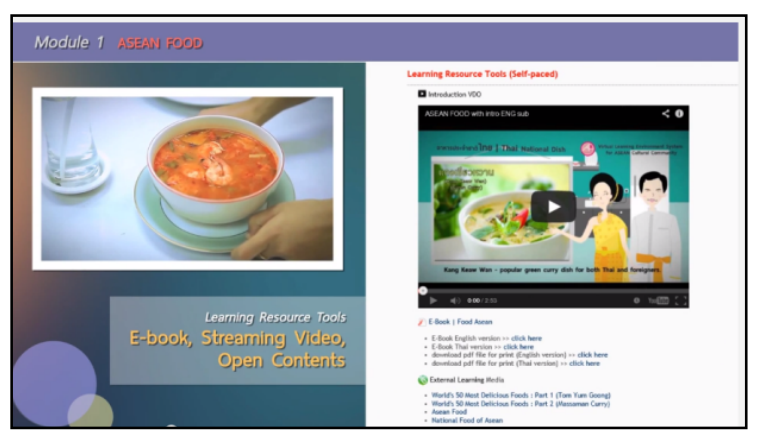

Figure 6. E-book and streaming video learning media on the subject of ASEAN Food

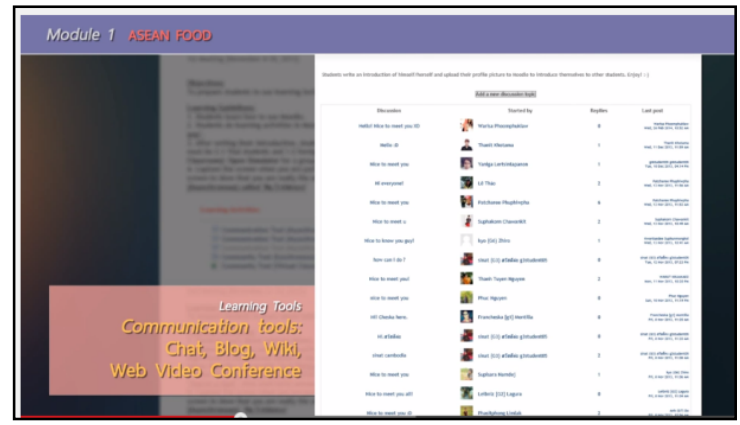

Figure 7. Activity among students from 5 ASEAN countries in the system. This is the 'Nice to Meet You' activity.
Content in e-book format and streaming media. Collaboration tools include 3D Community and Learning Management Systems which develop create skills in collaboration and communication. The content and learning tools are shown in Figures 6-11.
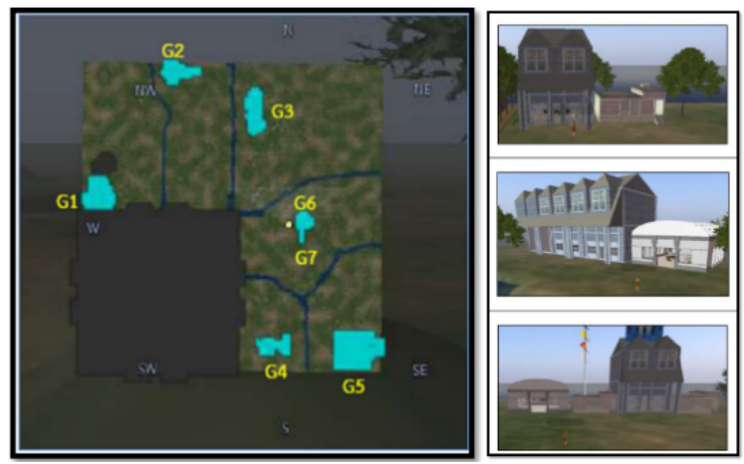

Figure 8. . Virtual Learning Environment developed by usingOpen Simulator showing a mini map of an island and houses of each group to join group activities

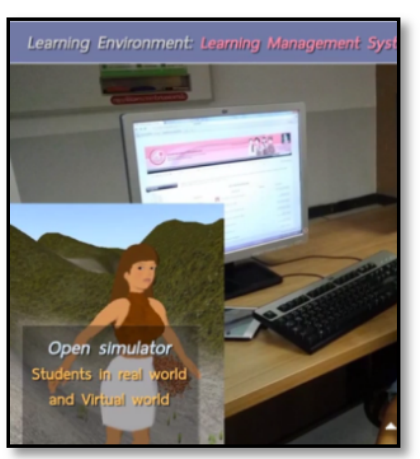

Figure 9. Virtual Learning Environment developed by using Open Simulator showing the avatar of students while participating in a group activity.

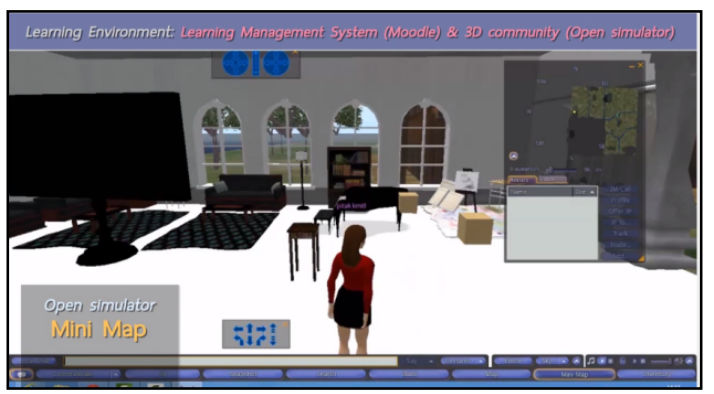

Figure 10. Virtual Learning Environment developed by using Open Simulator showing the avatar and a house of each group

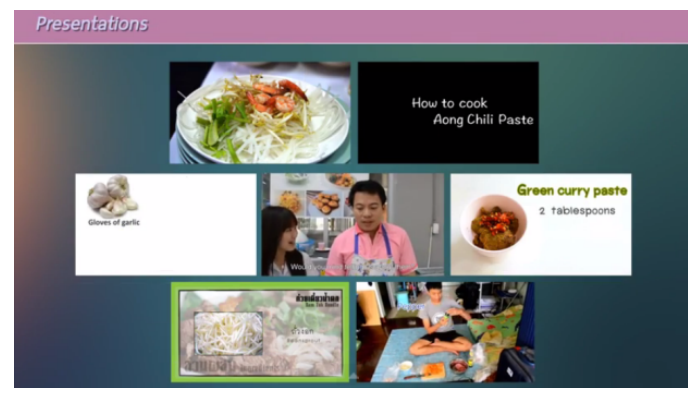

Figure 11. I-Video assignment or video on ASEAN Foodwhich requires participation of each group 
The system also includes highlights which enable the development of learners' $21^{\text {st }}$ century skills and promotes the understanding and recognition of social and cultural aspects of ASEAN. There are two highlights of the system as follows:

(1) The system is one stop learning service which consists of system and learning tools that are easy to use and allow quick access for (1) the development of learners' 21 st century skills in learning and innovation and (2) promotion of the understanding and recognition of social and cultural aspects of ASEAN. This is an important factor allowing the country to become a leader in the ASEAN community. The system provides (1) Tools including Moodle LMS, and VLE with a focus on the Virtual Classroom in the form of an avatar-based virtual reality/personal icons and virtual environment in the form of graphical representation such as a house and meeting room to exchange ideas and present in a virtual world. Cloud based tools have also been integrated. As for the creation of innovations of ASEAN students, activating print pages with digital AR content has been incorporated to motivate learners to create innovations and exchange learning ideas.

(2) The system was developed using Moodle and Open Simulator which are open source software that allow users to use and develop (the developer prepared the link to download the program, including Imprudence 1.3.2, Cumoodle56 which was developed from Moodle open source software using PHP and MySQL database, Open Sim0.731, and OAR Grid TCU which was developed from server software Open Simulator to create virtual 3D world, using C\# language and ran on Mono or Microsoft.NET using MySQL database). Also, there are other useful tools that facilitate international communication provided free of charge such as the Video Conference System: Red5 which was developed from Flash Streaming Server using JAVA (JREE) as a plug-in installed with Red5. There are also other social media and learning resources that focus on cloud technology and Open Educational Resources: OER. Some learning resources were developed to provide complete information that facilitate the exchange of ideas across cultures and are distributed for widespread usage.

3) Examine usage results, evaluate, and present the VLE system to enhance communication and collaboration skills for higher education learners in the ASEAN cultural community.

The comparison results between skills in communication and collaboration before and after studying through the designed VLE system were done to examine the effectiveness of the system. The results showed that the sample group of 30 students had average scores of skills in communication and collaboration at 2.83 with standard deviation at 0.33 . After studying, they had an average score of 4.52 with standard deviation at 0.25 . The results of the test of the differences between average score of skills in communication and collaboration before and after studying by using independent $t$-test indicated that the average achievement test score had a statistical difference at a 0.05 level of significance $(t=-24.335, p=0.00)$ as shown in Table IV.

Self-assessment scores were relevant with regard to the observation of behaviors and trace observation, project assignment scores, and the opinion survey scores. The
TABLE IV

The Difference Between Pre And Post Self-Assessment Scores OF COMMUNICATION AND COLLABORATION

\begin{tabular}{|c|c|c|c|c|c|}
\hline Assessment & $\mathbf{n}$ & $\bar{x}$ & S.D. & $\mathbf{t}$ & p \\
\hline Pre-test & 30 & 2.83 & 0.33 & \multirow{2}{*}{-24.335} & \multirow{2}{*}{0.00} \\
\hline Post-test & 30 & 4.52 & 0.25 & & \\
\hline
\end{tabular}

observation of behaviors and trace observation scores indicated that overall behaviors were at a very good level $(\overline{\mathrm{X}}=2.82$, S.D. $=0.45)$. The analysis of the project assignments show that the overall score for group work was at the highest level $(\overline{\mathrm{X}}=2.67, \mathrm{~S} . \mathrm{D} .=0.47)$. The analysis of the satisfaction survey of the VLE System, showed that the overall opinion was at the high level $(\overline{\mathrm{X}}=4.15$, S.D. $=$ $0.63)$.

\section{DISCUSSION AND CONCLUSION}

The aim of this research is to develop a VLE system to enhance the communication and collaboration skills of higher education learners in the ASEAN cultural community. The analysis of results provided the input elements of the system in order to ground the theoretical model. The 4 elements are: (1) Teaching Techniques and Collaborative Supporting Media, (2) Communication Tools, (3) Collaborative Learning, and (4) Roles. This is relevant to the literature review as follows.

1) Teaching Techniques and Collaborative Supporting Media Elements are relevant to the study of a framework on blended learning in a collaborative learning technique environment using Exploratory Factor Analysis [13]; the study of learning outcomes of two blended web-based lessons: communication and networks information that affect learning achievement and analytical thinking and the longevity of students' learning based on different achievement motivations [14]; and the study of the development of a prototype of blended learning in analysis and design of courses [15]. One conclusion from the research is that students learn more effectively through studentbased learning with active participation rather than passive participation [16]. The result of this study is also relevant to the finding of the study of an e-learning system in a blended learning environment to enhance the cognitive skills for learners in higher education [17] and the study on the development of web-based training for developing e-books [18]. From the research studies, it can be concluded that the teaching method and supporting media for collaboration that is appropriate for the development of a VLE system to enhance communication and collaboration skills should consist of various teaching techniques with various forms of supporting media. Students will learn by active participation via modern digital media which will not only improve their communication and collaboration skills, but also enhance cognitive skills, learning achievement, and promote lifelong learning. This is congruent with the result of this study where an analytical thinking with active learning approach was integrated for learners to participate in activities to compare similarities and differences among ASEAN member countries. Various technologies such as 3D avatars, panorama photos, video clips, e-books, video conferencing systems, and social media, were used as resources and means to communicate among ASEAN member students. After participating in the activities, each group with a combination of learners 
who were representatives from 3 ASEAN member countries were assigned to work on innovative projects which represent the ASEAN community identity. In so doing, communications and collaboration skills were enhanced throughout the processes working on the projects.

2) The communication tools element is relevant to the study of video conferencing between regional distance education centers, such as Sukhothai Thammathirat Open University [19]; the study of the development of information systems to support a course on organizational resource planning[20]; a case study to develop knowledge in learning of enterprise systems: ES course in the university in Australia [21]; and the study of analysis of the cultural factors affecting the proper design of website and electronic courseware for e-learning in ASEAN [22]. Based on the results of the research, it can be concluded that teaching techniques and supporting media for collaboration that are appropriate to develop a VLE to enhance communication and collaboration skills should consist of tools such as e-Learning on Moodle LMS. Multimedia should focus on open resources, video streaming, mobile learning, video conferencing and web applications which will help the communication and collaboration to become more effective. Instructors should prepare tools for students to facilitate learning and communication in both synchronous and asynchronous manners. Also, cloud technology and web application can help support and promote understanding in communication and collaboration without the limit of time, place, and differences between devices as well as the differences in culture, which are very important in the context of the ASEAN cultural community. The results are relevant to the screening variables in this research and it can be concluded that the most appropriate communication tools involve cloud technology with the use of mobile devices. In this study, the learners indicated that use of cloud technology and mobile devices could help enhance communication and collaboration skills as all learners were already equipped with such technologies in their daily life and there were no constraints in terms of time and space. Such results correspond with the reviewed literature which indicated that tools used in VLE could enhance students' engagement, motivation, and learning outcomes [6].

3) The collaborative learning element is relevant to the study of team-based learning and problem-based learning to promote standards of learning in accordance with the Thai Qualifications Framework for Higher Education [23]; the study of online networks: trends and ethics [24]; and the study of the factors affecting the behaviors in online social networks. The analysis of the frequency of factors in the research indicates that the factors that affected online social network behaviors were social features and norms of online social networks users, personal characteristics, individual motivation and ability, attitudes about security and privacy, entertainment value, and the benefits of using social networks [25]. It is also relevant to the study of the developing of blended e-learning based on constructivism with cognitive tools to enhance the knowledge of higher education learners [22]. Based on the results of the research, it can be concluded that collaborative learning can promote team learning of students by setting their roles and respecting other people's roles to create an environment for effective learning. The relevant variables from the screening are brainstorming, activitybased learning, group work and participation, and ex- change of experiences via communication tools in social networks and web applications which are channels to help students to work together. The tools are easy to access and relevant to students' behavior in the present. This is also relevant to the comparison results between skills in communication and collaboration of ASEAN learners in this study. In fact, the score results before and after studying via the activity-based learning approach in VLE showed that the sample group of 30 students had average scores of skills in communication and collaboration at 2.83 with standard deviation at 0.33 . After studying, they had an average score of 4.52 with standard deviation at 0.25 . The results indicate that average test scores were statistically different at a 0.05 level of significance $(t=24.33, p=0.00)$. Considering the changing behavior of ASEAN learners in this study after learning via the activity-based learning approach in VLE, overall behaviors were at a very good level $(\overline{\mathrm{X}}=2.82$, S.D. $=0.45)$. This is relevant to the analysis result of the assignment projects of skills in communication and collaboration where each group was comprised of 3 ASEAN student members. It was found that the overall score of group work was at the highest level $\bar{X}=2.67$, S.D. $=0.47)$. Such results are congruent with the literature indicating that the use of VLE promoted collaboration and communication by means of exchanging ideas, sharing thoughts, and exploring information together [7] and also the Thai government's globalization policies which address learners' need to be prepared for the advancement of information technology and social changes in joining the ASEAN community. Strong cooperation among the ASEAN countries can result in improving global competitiveness; therefore, higher education learners should be those who can communicate internationally and learn collaboratively with others to achieve the desired goal of learning [8]. To this end, the nature of the learning must involve students being part of a network of learning which spans boundaries through the use of technology [9].

(4) The roles element is relevant to the study of team work building, emphasizing how collaborative work results in quality work [26]; and the study of research-based guidelines for evaluating the educational service website: case study of Thailand Cyber University project [27]. Based on the results of the research, it can be concluded that appropriate roles should focus on capacity in collaborative learning. ASEAN learners should be aware of their roles in order to learn and make decision effectively. They will develop the feeling of being part of an ASEAN learning community. Examples of learning methods used in the community are active learning, activity-based learning, project-based learning, collaborative learning, and group learning. This is relevant to the screened variables and the analysis of results of the opinion survey on the VLE which show that the overall opinion was at the high level $\overline{\mathrm{X}}=4.15$, S.D. $=0.63)$, especially regarding learning and teaching which focuses on the capacity of ASEAN learners to communicate and work together.

Therefore, it can be seen why VLE is becoming widely used in higher education in numerous countries. VLE with special features has been developed to serve different aims. Examples are using VLE to teach occupational safety as compared to traditional lectures [7], the use of VLE in the form of web2.0 tools and Social Networking Sites (SNS) as an online community for language learning [6], and the use of VLE in the form of LMS and 3D virtual world to enhance the cognitive skills of higher educa- 
tion learners, self-paced learning, and lifelong learning in Thailand's education context [3]. Accordingly, it can be concluded that the findings of this study provide a framework for designing a VLE system to enhance communication and collaboration skills within the ASEAN community in line with its aim to create a people-centered community and promote the ASEAN identity. To fully achieve this, education has to be managed in a way as to encourage the recognition and understanding of social and cultural aspects. Therefore, such efforts should also focus on providing opportunities for learners to access a wide range of information and interact freely in learning activities with students from different countries. In so doing, learners can compare their similarities and differences throughout the learning process leading to the creation of a fuller ASEAN identity. To be able to create such an identity, communication and collaboration skills will be crucial. The results of this study suggest that the VLE system which helps achieve these goals should consist of four core elements: (1) teaching techniques and collaborative supporting media, (2) communication tools, (3) collaborative learning, and (4) defined roles, along with seven steps: step 1 - preparation (technology \& content), step 2 choosing an issue or topic to be studied, step 3 - setting working rules, step 4 - studying information and sharing ideas, step 5 - completing an assignment, step 6 - evaluation, and step 7 presentation. Elements and steps should highlight the use of a 3D virtual community and real time collaboration tools. In the study, such a system was designed and developed based on the research and was tested with a sample group of volunteer undergraduate students from 5 ASEAN countries. The analysis results indicate that the sample group had improved in regards to communication and collaboration skills which is supported by the scores obtained from the observation form and group assignment evaluation. Findings of this study may be used by administers and educators in setting up a VLE system to enhance communication and collaboration skills in higher education students while strengthening the ASEAN identity.

\section{ACKNOWLEDGMENT}

This paper was a part of the project funded by the National Research Council of Thailand (NRCT) in 2013. The authors would like to express our sincere appreciation to NRCT for the support. Sincere thanks must also go to Chulalongkorn University, Sukhothai Thammathirat Open University, and the Thailand Cyber University project, who are the supporting institutes. Special thanks also go to all advisors, and experts for their help and support in the study.

\section{REFERENCES}

[1] Jenkins, M., Browne, T., \& Walker, R. (2005). VLE Surveys: $A$ Longitudinal perspective between March 2001, March 2003, and March 2005 for Higher education in the United Kingdom. UK: UCISA-TLIG Learning and Teaching subgroup.

[2] Tick, A. (2013). Special Aspects of Teaching in Virtual Learning Environments. Aspects of Computational Intelligence, TIEI 2. 195-206. http://dx.doi.org/10.1007/978-3-642-30668-6 13

[3] Songkram, N., Khlaisang, J., Puthaseranee, B., Likhitdamrongkiat, M. (2015). E-learning System to Enhance Cognitive Skills for Learners in Higher Education. Procedia - Social and Behavioral Sciences, 174, 667-673. http://dx.doi.org/10.1016/j.sbspro.2015. $\underline{01.599}$
[4] Koskela, M., Kiltti, P., Vilpola, I., and Tervonen, J. (2005). Suitability of a Virtual Learning Environment for Higher Education. The Electronic Journal of e-Learning, 3(1), 21-30.

[5] Barab, S.A., Kling, R., \& Gray, J. H. (2004). Designing for Virtual Communities in the Service of Learning. United Kingdom: Cambridge University Press. http://dx.doi.org/10.1017/CBO97805 11805080

[6] Pellas, N. and Kazanidis, I. (2015). On the value of Second Life for students' engagement in blended and online courses: A comparative study from the Higher Education in Greece. Education and Information Technologies, 20, 445-466. http://dx.doi.org/10.1007/s10639-013-9294-4

[7] Weiss, J., Nolan, J., Hunsinger, J., and Trifonas, P. (2006). The International Handbook of Virtual Learning Environments. Dordrecht, Netherlands: Springer. http://dx.doi.org/10.1007/978-14020-3803-7

[8] Panich, V. (2012). Methods to Create Learning for Students in $21^{\text {st }}$ Century. Bangkok: Sodsri-Saritwong Foundation.

[9] Schrum, L. M. and Levin, B. B. (2009). Leading 21st-Century Schools: Harnessing Technology for Engagement and Achievement. United Kingdom: A SAGE Company.

[10] Khlaisang, J. \& Mingsiritham, K. (2013). Virtual Learning Environment System to Enhance $21^{\text {st }}$ Century Skills in Communication and Collaboration for Higher Education Learners in ASEAN Cultural Community Research. Research grant from National Research Council of Thailand in 2013.

[11] Harrison, R. \& Thomas M. (2009). Identity in Online Communities: Social Networking Sites and Language Learning. International Journal of Emerging Technologies \& Society, 7(2), 109-124

[12] Bureau of General Administration (2010). Office of Higher Education Commission, Ministry of Education, Thailand.

[13] Petchboonmee, P. and Theintong, M. (2012). Framework on Blended Learning under Collaborative Learning Technique Environment. The $2^{\text {nd }}$ Conference on Presenting Graduate Research of Sukhothai Thammathirat Open University.

[14] Champajan, K., Rengsuwan, C. \& Suksringam, P. (2012). Learning Outcome of Two Blended Web-Based Lessons: Communication and networks information that affect learning achievement and analytical thinking and the durability of students toward difference achievement motivation. Rajabhat Maha Sarakham University Journal, 7 (2): 95-103.

[15] Konseau, C., Krutjon S., \& Woraratpanya, K. (2011). Blended Learning for Activities in System Analysis and Design Course of Rajamagala University of Technology Isan, Sakonnakhnon Campus. Paper presented at the The $5^{\text {th }}$ National Conference on Computing and Information Technology.

[16] Sangonsai, K. (2011). Active Learning. Walailak University PBL Pamphlet, 4(2): 4-6.

[17] Khlaisang, J. \& Likhitdamrongkiat, M. (2015). E-learning System in Blended Learning Environment to Enhance Cognitive Skills for Learners in Higher Education. Procedia - Social and Behavioral Sciences, 174, 759-767. http://dx.doi.org/10.1016/j.sbspro.2015. 01.612

[18] Runwat, A. \& Suwannoi, P. (2011). The Development of Webbased Training for Developing e-Book. Rajabhat Maha Sarakham University Journal (Humanities and Social Sciences), (1)8, 111 124

[19] Thewarat, C. (2010). Research from Routine Tasks on the Study of Problems and Needs of Educational Technology of Graduated Students of Regional Distance Education Centers, Sukhothai Thammathirat Open University: Sukhothai Thammathirat Open University.

[20] Liamprawat, S. (2013). Research project "The Development of Information System to Support Information for Organization Resources Planning Course". College of Arts, Media and Technology, Chiang Mai University.

[21] Rabaa'i, A.A., Bandara, W., \& Gable, G.G. (2010). Enterprise systems in universities: a teaching case. In $16^{\text {th }}$ Americas Conference on Information Systems (AMCIS), August 12-15, 2010. Lima, Peru.

[22] Khlaisang, J. (2012). Development of Pedagogical Blended ELearning Model Using Cognitive Tools Based Upon Constructivist Approach for Knowledge Construction in Higher Education. 
Proceedings of the Fourth International e-Learning Conference 2012, organized by the Thailand Cyber University Project, Office of the Higher Education Commission, Bangkok, Thailand, June 14, 2012.

[23] Promprakay, P. \& Thurangan, S. (2013). The Case Study of Teambased Learning and Problem-based Learning to Promote Standards of Learning in Accordance with Thai Qualifications Framework for Higher Education 2552 B.E. (TQF). Paper presented at the Bangkok University Conference, Bangkok University, Kluy Nam Thai Campus.

[24] Tithimatchima, V. (2010). Online Network: Trend, Phenomenon, and Ethics. Executive Journal, (4)30, .156 150

[25] Kroysawad, N. (2010). The Factors Affecting the Behaviors in Online Social Network. Librarians and Information, Khon Kaen University, Nong Khai Campus, (3)28, .88 81

[26] Ngamkanok, S. Team Building. Journal of Education (1)19: October 2007-January 2008.

[27] Khlaisang, J. (2015). Research-based Guidelines for Evaluating Educational Service Website: Case Study of Thailand Cyber University Project. Procedia - Social and Behavioral Sciences, 174, 751-75 http://dx.doi.org/10.1016/j.sbspro.2015.01.611

\section{AUTHORS}

Jintavee Khlaisang is an Associate Professor at the Department of Educational Technology and Communications, Chulalongkorn University, Bangkok 10330 Thailand. Her research interests include Virtual Learning Environment, E-learning, and Blended Learning Environment (jintavee.m@chula.ac.th).

Kemmanat Mingsiritham is an Assistant Professor at the Office of Educational Technology, Sukhothai Thammathirat Open University, Nonthaburi 11120 Thailand. Her research interests include Virtual Learning Environment and Distance Learning. (kemmanat.min@hotmail.com)

This work was supported by the National Research Council of Thailand (NRCT). Submitted 20 January 2016. Published as resubmitted by the authors on 11 March 2016. 